\title{
El compostaje y los índices para evaluar su estabilidad
}

Raúl Darío Zapata Hernández Docente, Facultad de Ciencias Universidad Nacional de Colombia, Sede Medellín.

Cómo citar:

Zapata-Hernández, R. D. (2009). El compostaje y los índices para evaluar su estabilidad. En Sociedad Colombiana de la Ciencia del Suelos \& Centro Nacional de Investigaciones de Café (Eds.), Materia orgánica biología del suelo y productividad agrícola: Segundo seminario regional comité regional eje INTRODUCCIÓN cafetero (pp. 33-42). Cenicafé. https://doi.org/10.38141/10791/0003_2

El compostaje es un proceso biológico, en medio aeróbico, en el cual los sólidos húmedos son transformados a formas más estables llamadas sustancias similares al humus (likehumic) o compost (Senesi, 1998). Las principales fuentes de sustratos de materiales para el compostaje son los deshechos de la agricultura (residuos de cosecha y estiércoles), residuos de la industria de alimentos (enlatadoras, cervecerías, lecherías, etc.), desechos de aserríos (aserrín, viruta, etc), la fracción orgánica de los residuos urbanos (basuras separadas en la fuente, lodos de depuradora, las podas de las áreas verdes de la ciudad), deshechos de la fermentación, residuos de papel y celulosa, entre otros.

En el proceso de compostaje exitoso se deben optimizar cuatro parámetros, los cuales son aireación, temperatura, humedad y, algunas veces, el pH (Senesi y Brunetti, 1996). La retención de calor o autocalentamiento es la característica diferencial más importante entre el compostaje y los demás tratamientos anaeróbicos (lodos de depuradoras). En el compostaje se busca que la energía generada en forma de calor sea disipada. Se trata de disponer el material, en tal forma, que las tasas de producción de energía, resultante del metabolismo microbiano, sea superior a la tasa de la energía disipada a través de la superficie de la pila. Las materias altamente biodegradables se suelen añadir a la pila de compostaje para incrementar el metabolismo y generar más calor.

\section{EL PROCESO DE COMPOSTAJE}

El proceso de compostaje incluye básicamente tres fases:

- Una fase inicial, durante la cual los materiales fácilmente degradables son descompuestos.

- Una fase termófila, durante la cual materiales proteínicos, celulíticos y similares, son degradados con la producción de dióxido de carbono, agua y iones. Se forman compuestos orgánicos estables, se eliminan sustancias fitotóxicas y otros patógenos. 
- Una fase de estabilización, en la cual la temperatura declina, disminuye la velocidad de descomposición y la masa es recolonizada por organismos mesófilos. Se llega a material orgánico estable o compost maduro. Un eventual estado de curado, el cual consiste en la prolongación del estado de estabilización y mineralización, y va más allá del estado de madurez.

Se ha dicho que el compostaje es un proceso aeróbico, aunque en la mayoría de las situaciones se producen condiciones anaeróbicas a escala microscópica. No obstante, la biodegradación ocurre en un ambiente oxidado mayoritariamente, si la aireación es manejada adecuadamente.

Durante el proceso de descomposición, la materia orgánica es consumida por los organismos y produce dióxido de carbono, agua, calor y otras sustancias. Bajo condiciones óptimas, en cuanto al tiempo, el compostaje pasa por tres etapas: 1) una fase de temperatura moderada o mesófila, la cual puede durar un par de días, 2) una fase de alta temperatura o termófila, que puede durar de varios días a varias semanas, y finalmente, 3) una fase de enfriamiento o de maduración que puede tomar varios meses.

Durante estas fases pueden predominar diferentes comunidades de microorganismos. En la fase inicial, la descomposición es realizada por microorganismos mesófilos, que consumen aquellas sustancias solubles y de fácil degradación como azúcares, aminoácidos, ácidos grasos de cadena corta, entre otros. Se inicia así, un rápido incremento de la temperatura. El calor generado por la actividad metabólica, a medida que sucede la descomposición de los restos orgánicos por parte de los microorganismos, es superior al calor que se disipa.

Los perfiles de temperatura, generalmente comienzan con una fase inicial de corta duración, asociada a la aclimatación de los microorganismos. Después, la temperatura se incrementa en forma exponencial hasta alcanzar un nivel máximo. Si la temperatura entra en el rango termófilo $\left(>45^{\circ} \mathrm{C}\right.$ ) se producen cambios sustanciales en la población microbiana. Los microorganismos que son incapaces de tolerar altas temperaturas mueren o forman esporas, mientras que las bacterias termófilas se ven favorecidas y predominan. Sin embargo, si la temperatura alcanza valores más altos (55 ó $60^{\circ} \mathrm{C}$ ), las bacterias termófilas se ven afectadas y disminuye su actividad.

Normalmente, las pilas de compost pasan por el rango mesófilo $\left(30\right.$ a $40^{\circ} \mathrm{C}$ ) y termófilo (50 a $60{ }^{\circ} \mathrm{C}$ ). La selección del rango de funcionamiento de una determinada pila de compost, se debe basar en investigaciones realizadas a escala piloto y con los materiales de los que se pueda disponer fácilmente. En la Figura 1, se muestra el perfil típico de temperatura de una pila de compostaje y las fases que determina.

En la Figura 1 se observa que bajo condiciones controladas, la temperatura disminuye tras cierto lapso de tiempo. Esta disminución está asociada con la reducción de las reservas de alimento (Figura 2) y a la constante reducción en la actividad microbiológica. El período de compostaje activo se considera completo a medida que la pila se enfría y las temperaturas dentro de ella, se aproximan a la temperatura ambiente. 


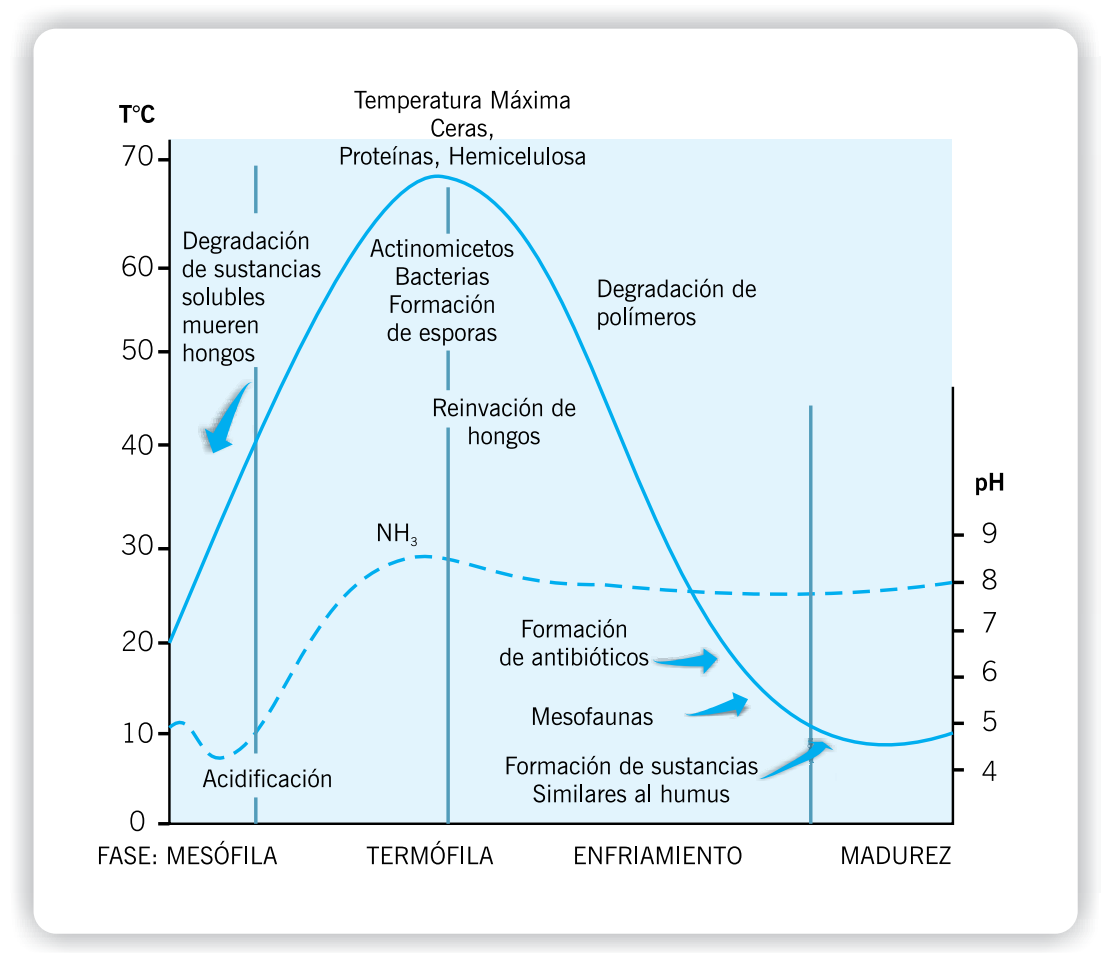

Figura 1. Cambios de la temperatura y del $\mathrm{pH}$ durante las diferentes etapas del proceso de compostaje.

Otras características del proceso de compostaje son los cambios del aspecto y el olor de la pila. Inicialmente, se distinguen la naturaleza y los olores que identifican al material. Al final del proceso de compostaje el material tiene un olor y aspecto similares a suelo orgánico. En el producto final no se identifican los materiales originales, el tamaño de la pila se reduce drásticamente; además, el color, aspecto y olor, son el resultado de la biodegradación en un medio oxidado de la materia orgánica. Esta conversión de la masa inicial a un producto final estable, semejante al humus, se logra con una pérdida fundamental de dióxido de carbono y agua, principalmente.

Durante la fase termófila, las altas temperaturas ayudan a la descomposición de proteínas, grasas y carbohidratos complejos como celulosa y hemicelulosa, el mayor componente estructural de las plantas. Cuando se termina la suplencia de estos compuestos, fuentes de energía, la temperatura del compost decrece y los organismos mesófilos colonizan de nuevo la pila, y se inicia la fase de maduración o curado de la materia orgánica similar al humus.

Como se muestra en la Figura 2, el proceso de compostaje define cada uno los estados de degradación, enmarcados en el tiempo. El primer estado es de rápida descomposición de los compuestos de alta energía como carbohidratos y proteínas, por parte de las 


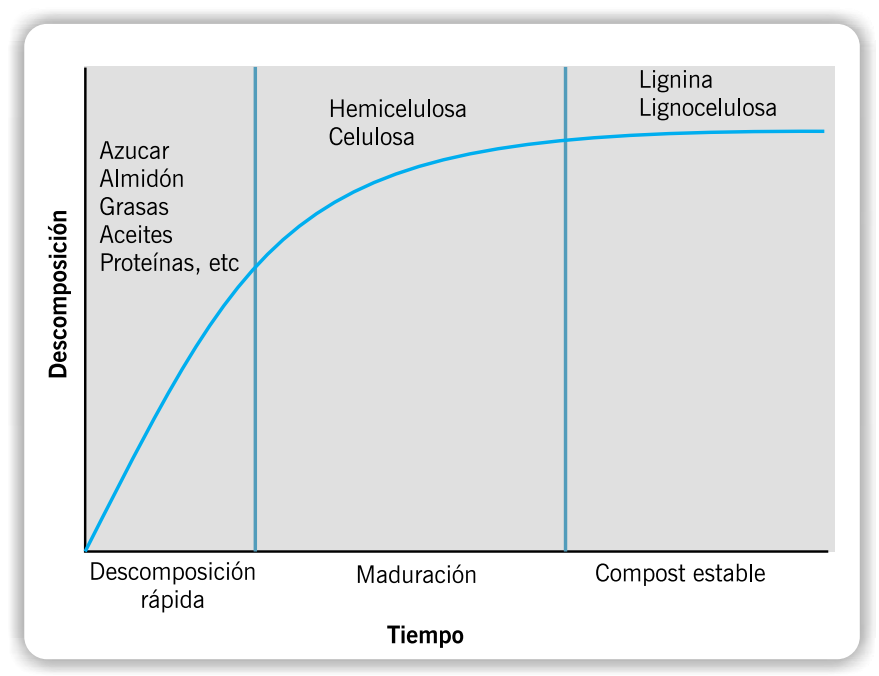

Figura 2. Degradación de distintos tipos de sustancias con el tiempo, en los distintos estados del proceso de compostaje.

bacterias, y ocurre una alta liberación de energía, en forma de calor, dentro de la pila. Con este aumento de temperatura se incrementa la actividad microbial, que puede llegar a inactivarse cuando alcanza valores muy altos. Durante el segundo estado la población de microorganismos cambia; aquí se distinguen principalmente hongos y actinomicetes, que descomponen celulosa y hemicelulosa, que son compuestos difíciles de desdoblar y producen poca energía. Durante este estado ocurre poca transformación de los compuestos orgánicos de la pila. En el tercer estado, los materiales presentes en el compost continúan su proceso de condensación, llegando a formas más estables.

\section{Pruebas de evaluación de madurez del compost}

No existe una definición universal para caracterizar la madurez del compost (Senesi y otros, 1996). Esta madurez es un nivel particular de estabilidad biológica y de actividad físico-química, que permite la utilización inmediata de la biomasa transformada, para diferentes usos, como son la producción de cultivos, la recuperación del suelo o simplemente para su disposición en el suelo, sin que generen contaminación del agua y el aire, es decir, tener un material ambientalmente limpio.

Los criterios de madurez y calidad del compost incluyen, entre otros, los siguientes análisis:

- Apariencia física

- Relación C/N

- $\mathrm{CIC}$

- Concentración de $\mathrm{NO}_{3}{ }_{3}, \mathrm{NO}_{2}{ }^{-}$

- Relación $\mathrm{NO}_{3}{ }^{-} / \mathrm{NH}_{4}{ }^{+}$

- $\mathrm{pH}$

- Sustancias biodegradables, análisis de fibra cruda

- Test enzimático y microbiológico

- Fosfatasa alcalina 
- Bioensayos con plantas

- Índices empíricos de humificación

- Análisis elemental, grupos funcionales, contenido de metales trazas, técnicas espectroscópicas

- Fracción semejante a ácidos húmicos y fúlvicos obtenidos en el compost y su comparación con los correspondientes ácidos húmicos y fúlvicos de los suelos

En general, se espera como indicativo de madurez y estabilidad del compost, que la Relación C/N sea menor o igual a 15, y la ClC, asociada a las sustancias similares al humus, sea igual o mayor a $60 \mathrm{cmol} / 100 \mathrm{~g}$ de compost.

Entre los índices empíricos de humificación se tienen:

Índice de Humificación (IH):

$$
\mathrm{IH}=\mathrm{C}_{\mathrm{NH}} / \mathrm{C}_{(\mathrm{AH}+\mathrm{AF})}
$$

Donde:

$\mathrm{NH}$ : fracción no húmica (compuestos orgánicos no humificados extraídos con la solución alcalina),

AH y AF: fracciones de ácido húmico y ácido fúlvico, respectivamente, extraídas con la solución alcalina y separadas por precipitación en medio ácido.

Los valores reportados son:

$\mathrm{IH} \leq 1$ : compost maduro

IH 1-2: compost parcialmente maduro

$\mathrm{IH}>2$ : compost inmaduro

Para la mayoría de los suelos se tiene un IH entre 0,133 y 0,278.

\section{Índice y relaciones de humificación:}

Relación de humificación $1\left(\mathrm{HR}_{1}\right): \mathrm{AH} / \mathrm{FF}$

Relación de humificación $2\left(\mathrm{HR}_{2}\right): \mathrm{AH} / \mathrm{AF}$

\section{LAS SUSTANCIAS SIMILARES AL HUMUS}

No se puede llamar sustancias húmicas o humus a todo material que se ha transformado biológicamente mediante procesos oxidativos, controlados o no por el hombre, como es el caso del compost (Senesi, 1996; Kumada, 1987). El proceso de humificación de las sustancias orgánicas, ya sean restos orgánicos o materiales compostados, que llegan al suelo, está sometido, al igual que la parte inorgánica, a la acción de los factores formadores del suelo definidos por Jenny (1941), hace más de cinco décadas. Es por esta razón que la producción del humus es un proceso netamente pedológico, fuera de la acción temporal del hombre. Al ser humano sólo le quedan dos opciones: la conserva o la destruye, pero nunca podrá producir sustancias húmicas. 


\section{Índices de humificación}

Algunos índices usados para evaluar la humificación de los suelos se han usado para evaluar el proceso de compostaje y la madurez de éste. Los siguientes son los índices más usados:

- Relación de humificación: $100\left(\mathrm{C}_{\text {hum }} / \mathrm{C}_{\text {org }}\right)$

- Índice de humificación: $100\left(\mathrm{C}_{\mathrm{AH}} / \mathrm{C}_{\text {org }}\right)$

- Porcentaje de ácidos húmicos $(\mathrm{AH}): 100\left(\mathrm{C}_{H A} / \mathrm{C}_{\text {hum }}\right)$

- Relación ácido húmico/ácidos fúlvico: $\mathrm{C}_{\mathrm{AH}} / \mathrm{C}_{\mathrm{AF}}$

- Índice RF: $1000\left(\mathrm{~K}_{600} / \mathrm{C}_{\mathrm{AH}}\right)$

- Relación de absorción: $\Delta \log \mathrm{K}=\log \mathrm{K}_{400}-\log \mathrm{K}_{600}$

El Corg es el carbono total del material medido por combustión húmeda. El valor de Chum es el contenido de carbono en el extracto alcalino del material. Los valores CAH y CAF hacen referencia al contenido de carbono en las fracciones precipitada y soluble en ácido del extracto alcalino. K se refiere a la absorbancia a 400 y $600 \mathrm{~nm}$, y RF es la cantidad de absorbancia que produce una cantidad de carbono de ácidos húmicos.

El esquema de extracción de sustancias similares al humus, que se le realiza al compost, se presenta en la Figura 3.

En las Tablas 1 a la 3 se presentan los valores elementales de $\mathrm{C}, \mathrm{H}, \mathrm{N}$ y O, los análisis de extractos acuosos y la cantidad de sustancias húmicas y sus fracciones extraídas de las muestras de compost tomadas de la pila, en diferentes períodos, durante el proceso de compostaje de desechos de flores.

De acuerdo con el análisis elemental, en la Tabla 1 se observa que el contenido de $\mathrm{C}$ disminuye con el tiempo; esta pérdida es casi del 8\% durante los 151 días del proceso.

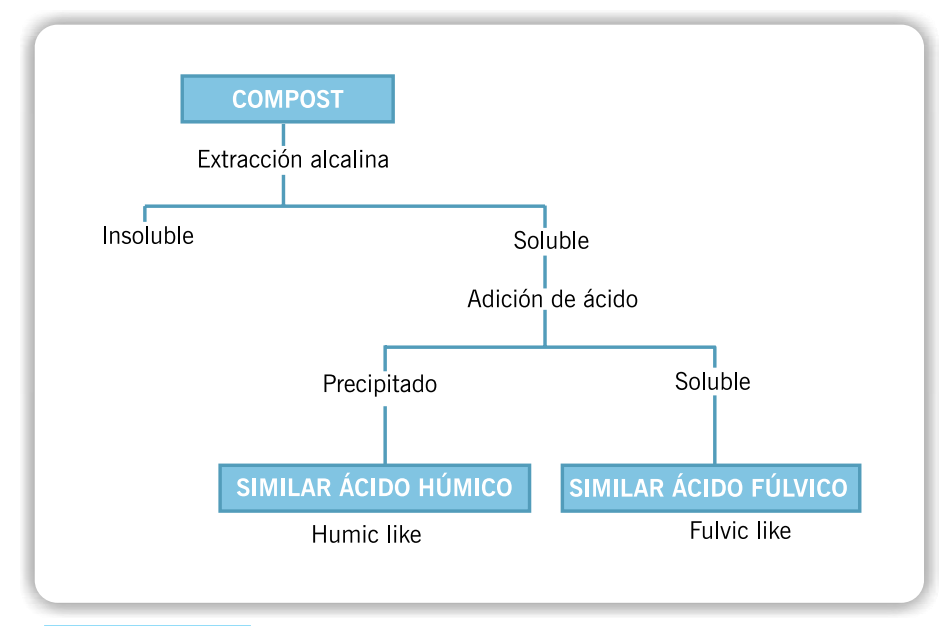

Figura 3. Esquema de extracción de sustancias similares al humus de un compost (Senesi, 1996). 
Tabla 1. Análisis elemental de los desechos de flores durante el proceso de compostaje de flores (Arango, 1998).

\begin{tabular}{|c|c|c|c|c|c|c|}
\hline \multirow{2}{*}{ Tiempo (Días) } & $\mathrm{C}$ & $\mathbf{H}$ & $\mathbf{N}$ & 0 & \multirow{2}{*}{$\mathbf{C} / \mathrm{N}$} & \multirow{2}{*}{$\frac{\mathrm{CIC}}{\mathrm{meq} / 100}$} \\
\hline & \multicolumn{4}{|c|}{$\%$} & & \\
\hline 0 & 48,78 & 7,50 & 2,75 & 40,58 & 27,76 & 34,94 \\
\hline 12 & 49,19 & 7,54 & 2,15 & 40,89 & 22,83 & 41,24 \\
\hline 27 & 48,72 & 7,29 & 2,03 & 41,67 & 21,11 & 48,54 \\
\hline 41 & 46,94 & 6,95 & 2,16 & 43,63 & 21,03 & 52,22 \\
\hline 63 & 45,34 & 6,69 & 2,62 & 45,01 & 17,08 & 58,78 \\
\hline 90 & 42,98 & 6,38 & 2,54 & 47,75 & 16,92 & 67,68 \\
\hline 122 & 42,31 & 6,37 & 2,63 & 48,25 & 15,95 & 78,99 \\
\hline 151 & 40,93 & 6,22 & 2,64 & 49,79 & 14,99 & 82,74 \\
\hline
\end{tabular}

El hidrógeno es otro elemento que disminuye durante el proceso. En contraposición, el oxígeno se incrementa.

En contraste con la respuesta de los anteriores elementos, el nitrógeno no muestra cambios durante el proceso de compostaje. Podría pensarse que es un elemento que se recicla en la pila, cambiando de formas químicas, pero manteniendo constante su contenido. Cabe anotar que al disminuir el contenido de carbono y mantenerse constante el contenido de nitrógeno, diminuye la relación $\mathrm{C} / \mathrm{N}$.

La capacidad de intercambio de cationes $(\mathrm{CIC})$, se incrementa constantemente durante el tiempo de compostaje. Como la CIC en las sustancias similares al humus, que se están formando durante el proceso, están muy asociadas a grupos funcionales ácidos, que contienen oxígeno, lo cual explica la correlación entre estas dos variable.

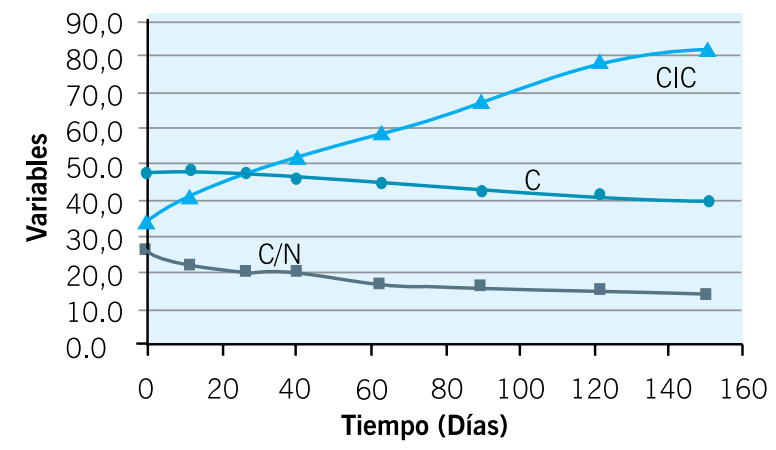

Figura 4. Variación en el tiempo del contenido de carbono (\%), capacidad de intercambio de cationes (ClC, cmol. kg-1) y de la relación carbono nitrógeno $(\mathrm{C} / \mathrm{N})$, de los desechos de flores, durante el proceso de compostaje de los residuos de flores (Figura elaborada con datos de Arango, 1998). 
En la Figura 4, se observan las tendencias del cambio del contenido de $\mathrm{C}$ en el tiempo de compostaje, de la relación $\mathrm{C} / \mathrm{N}$ y de la $\mathrm{CIC}$. El mayor cambio ocurre en la capacidad de retener cationes, posiblemente asociados al aumento del contenido de oxígeno presente en los grupos funcionales ácidos. La disminución de la relación $\mathrm{C} / \mathrm{N}$, de 28 a 15, en el tiempo de compostaje es de los mejores índices para el control del proceso (Senesi y Brunetti, 1996, Comunicación personal Prof. Carlos Peláez, Universidad de Antioquia, Medellín).

Otras de las formas de evaluar el proceso de compostaje es por medio de extractos acuosos de compost durante el proceso (Tabla 2). La facilidad de obtener extractos acuosos de las muestras tomadas de la pila de compost, principalmente en las etapas iniciales, hacen de esta metodología una buena práctica para evaluar el proceso.

En Tabla 2 se observa una tendencia similar, con valores menores, debido a que la relación $\mathrm{C} / \mathrm{N}$ disminuye con el tiempo de compostaje. Los contenidos de $\mathrm{C}$ y $\mathrm{N}$ aumentan con el tiempo, debido a la extracción que hace el agua de sustancias orgánicas solubles, que no hacen parte del compost. La relación $\mathrm{NO}_{3} / \mathrm{NH}_{4}$ aumenta en el tiempo, en respuesta a la condición oxidativa del proceso, situación que es inherente a éste.

La relación de absorción a 465 y $665 \mathrm{~nm}$, referida como E4/E6 se ha usado ampliamente con fines de caracterización. Esta relación para ácidos húmicos es usualmente menor de 5,0 y para los ácidos fúlvicos está en el rango entre 6,0 y 8,5. La relación decrece cuando se incrementa el peso molecular y la condensación, por esto se toma como un índice de humificación. Así, valores bajos de la relación E4/E6 pueden indicar un relativo alto grado de condensación de constituyentes aromáticos, e indican la presencia de estructuras alifáticas. Los valores de la relación E4/E6 de extractos acuosos, que se presentan en la Tabla 2, aumentan con el tiempo de compostaje; aun cuando no es posible decir que se tienen estos ácidos en el compost, sí es una medida que se puede utilizar para el control del proceso.

En la Tabla 3 se tienen las cantidades de sustancias similares al humus que se forman durante el proceso de compostaje. Las sustancias similares a la sustancia húmica (SSH)

Tabla 2. Análisis de extractos acuosos (1:10), durante el proceso de compostaje de flores (Arango, 1998).

\begin{tabular}{|c|c|c|c|c|c|c|}
\hline Tiempo & C & $\mathbf{N}$ & $\mathrm{C} / \mathrm{N}$ & $\mathrm{NO}_{3} / \mathrm{NH}_{4}$ & E4/E6 & $\triangle \mathrm{LOGK}$ \\
\hline Días & \multicolumn{2}{|c|}{$\%$} & & & & \\
\hline 12 & 1,23 & 0,33 & 3,73 & 0,15 & 4,62 & 0,576 \\
\hline 41 & 1,51 & 0,43 & 3,51 & 2,11 & 4,35 & 0,638 \\
\hline 63 & 1,63 & 0,37 & 4,40 & 5,03 & 5,27 & 0,722 \\
\hline 90 & 1,63 & 0,34 & 4,79 & 7,23 & 5,17 & 0,713 \\
\hline 122 & 2,54 & 0,46 & 3,09 & 7,11 & 4,74 & 0,675 \\
\hline 151 & 1,99 & 0,44 & 3,09 & 6,00 & 5,84 & 0,767 \\
\hline
\end{tabular}


Tabla 3. Cantidad de sustancias similares al humus (like-humus) y sus fracciones extraídas de compost de desechos de flores (Arango, 1998).

\begin{tabular}{|c|c|c|c|c|c|}
\hline Tiempo & SSH & SAH & SFF & SAF & SFNH \\
\hline Días & \multicolumn{5}{|c|}{$\mathbf{g}$ de C/100g compost } \\
\hline 12 & 27,31 & 13,81 & 13,50 & 5,48 & 8,02 \\
\hline 41 & 34,65 & 19,93 & 14,72 & 5,93 & 8,79 \\
\hline 63 & 41,14 & 25,44 & 15,70 & 6,30 & 9,40 \\
\hline 90 & 60,91 & 33,80 & 17,11 & 6,79 & 10,32 \\
\hline 112 & 65,88 & 47,09 & 18,80 & 7,31 & 11,49 \\
\hline 151 & 61,38 & 43,97 & 17,40 & 7,10 & 10,31 \\
\hline
\end{tabular}

aumentan con el tiempo del proceso, igualmente que las demás fracciones. El mayor incremento se da en los primeros 90 días para luego estabilizarse en todas las fracciones.

La Figura 5 relaciona dos parámetros que serían buenos indicadores del control de proceso de compostaje. La relación $\mathrm{C} / \mathrm{N}$ y el contenido de $\mathrm{C}$ de la sustancia similar a la sustancia húmica (SSH), no cambian después de que el proceso se ha estabilizado, en este caso a los 90 días, lo cual indica que en estas condiciones el compost ha llegado a una condición estable.

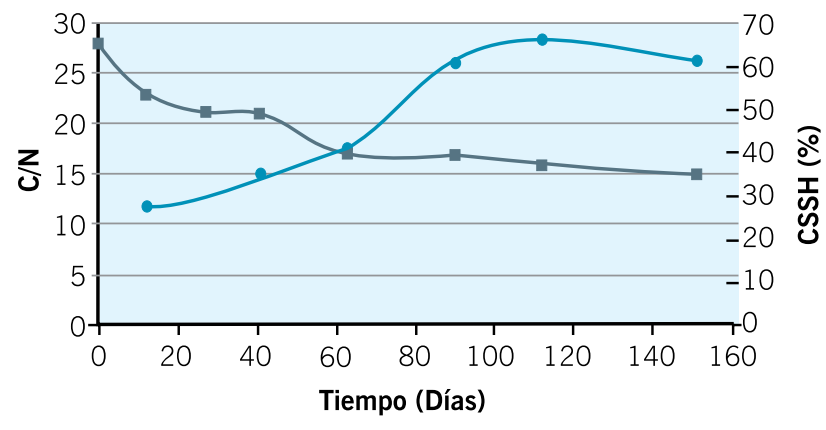

Figura 5. Cambios del contenido de carbono de sustancia similar a la sustancia húmica (SSH) y la relación carbono nitrógeno en el tiempo del compostaje de desechos de flores (-Relación $\mathrm{C} / \mathrm{N} ; \bullet \mathrm{C}$ de sustancias húmicas). 


\section{CONCLUSIÓN}

Es posible identificar estados finales de compostaje utilizando índices de humificación. De esta forma se puede eliminar la subjetividad que se tiene para definir el estado final y la calidad del compost, dado que estos índices son constantes en el tiempo, lo cual indica que bajo estas condiciones los materiales orgánicos son estables y estarán listos para ser aportados al suelo, donde se inicia un verdadero proceso de humificación.

\section{Literatura citada}

Arango, G. 1998. Diseño y montaje de una unidad experimental para evaluar un proceso de compostación: cinética, y parámetros de calidad del compost. Tesis de Master Química, Instituto de Química, Universidad de Antioquia, Medellín, 54 p.

Jenny, H. 1941. Factors and soil formation. A system of quantitative pedology. McGraw-Hill. New York, $281 \mathrm{p}$.

Kumada, K. 1987. Chemistry of soil organic matter. Japan Scientific societies Press. Tokyo. 241p.

Senesi, N; Miano, T.M.; Brunetti, G. 1996. Humic-like substances in organic amendments and effects on native soil humic substances, Chapter 14. En (ed) Piccolo A. Humic substances in terrestrial ecosystems. Ed. Elsevier Science B. V. Amsterdam.531-593p.

Senesi, N. 1998. Curso sobre compost y materia orgánica del suelo. Universidad Nacional de Colombia, Sede Medellín.

Senesi, N.; Brunetti, G.. 1996. Chemical and physico-chemical parameters for cuality evaluation of humic substances produced during composting. In: The science of composting. (ed) M. Bertoldi et al. Ed. Blackie Academic and Professional. Londres.195-212p.

Stevenson, F.J. 1982. Humus chemistry. New York (USA), Willey. 232p. 